\title{
Hip and Groin Injury Prevention in Elite Athletes and Team Sport - Current Challenges and Opportunities
}

\author{
Steven M. Short, DPT, SCS, FAAOMPT, CSCS $^{1}$ a , Cameron W. MacDonald, DPT, GCS, OCS, FAAOMPT ${ }^{2}$, Donald Strack, \\ DPT, ATC, OCS, FAAOMPT ${ }^{3}$ \\ 1 Physical Therapy and High Performance, Denver Nuggets Basketball Club, ${ }^{2}$ School of Physical Therapy, Regis University, ${ }^{3}$ Oklahoma City Thunder \\ Physical Therapy, Oklahoma City Thunder Basketball Club \\ Keywords: risk reduction, injury prevention, hip, groin, adductor \\ https://doi.org/10.26603/001c.18705
}

\section{International Journal of Sports Physical Therapy}

Vol. 16, Issue 1, 2021

\begin{abstract}
Hip and groin injury (HAGI) has been reported as a source of significant time loss in elite sport. Field and court-based sports such as basketball, football, hockey, soccer, among others, require explosive multiplanar movement in single stance and high-speed change of direction. Often situations arise where sub-optimal pre-season training has occurred or congested in-season competition minimizes physiologic recovery periods between bouts of physical activity, both of which could magnify concomitant existing risk factors and increase injury risk. Identification and management of HAGI can be challenging as numerous structures within the region can be drivers of pain and injury, especially when considering the likelihood of concurrent pathology and injury reoccurrence. Focused prevention strategies have been suggested, but their practical clinical implementation has not been heavily investigated across the sporting spectrum. The purpose of this commentary is to review the historical and current state of HAGI, while focusing on applying evidence and clinical experience towards the development of future risk reduction strategies.

Level of evidence: 5
\end{abstract}

\section{IS IT INJURY OR MANAGEMENT THAT IS ON THE RISE?}

Clinical practice related to hip and groin injury (HAGI) has progressed from broad terminology (i.e chronic athletic groin pain, Gilmore's groin, athletic pubalgia, etc) regarding diagnosis and management to highly specific subgrouping of regional diagnoses related to pathoanatomics. Recent consensus statements have attempted to define current best practice in the diagnosis and management of HAGI. 1,2 While beyond the scope of this paper to explore all sources of HAGI, it is important to note some common structures and associated athletic-related pathologies. These include, but are not limited to, bony structures (femur, femoral head and neck, acetabulum, pubis) extra-articular, (adductor musculature, iliopsoas, rectus femoris), intra-articular, (acetabular labrum, acetabular cartilage, pubic symphysis), and neural structures. (Figure 1) The noted anatomy may be accordingly impacted by sprain, strain, tendinopathy, bony and/or joint stress, osteoarthritis, or a combination of pathology such as osteoarthritis and labral degeneration. Many strategies have been implemented to properly diagnose injury as demonstrated by the Doha agreement ${ }^{1}$ and have been expanded upon in follow-up clinical commentaries. ${ }^{3}$ These guidelines have recommended HAGI to be defined specifically as adductor, pubic, inguinal, iliopsoas, or hip-related groin pain. ${ }^{1}$

Improved diagnostic capabilities and clinical awareness of HAGI has likely resulted in an increased incidence and prevalence of related diagnosis, which has coincided with expanded coverage within the literature. This combination of factors suggests the presence of historical underdiagnosis, ${ }^{4,5}$ the possibility of modern day overdiagnosis, ${ }^{2,6}$ and creates the potential for bias in management strategies and reported outcomes. The heterogeneity related to the comprehensive research and management of HAGI has made best practice elusive, especially when targeting isolated structures. ${ }^{7,8}$ Syndrome-based recommendations ${ }^{2,9}$ have been endorsed to better appreciate the complex, regionally interdependent and often concomitantly pathological ${ }^{9-11}$ nature about the hip, pubis, and lumbopelvis. Regional im-

\footnotetext{
a Corresponding author:

Steven Short

Physical Therapy and High Performance - Denver Nuggets Basketball Club, Denver, CO

Email: steveshortdpt@gmail.com

Phone: 906-282-4747
} 


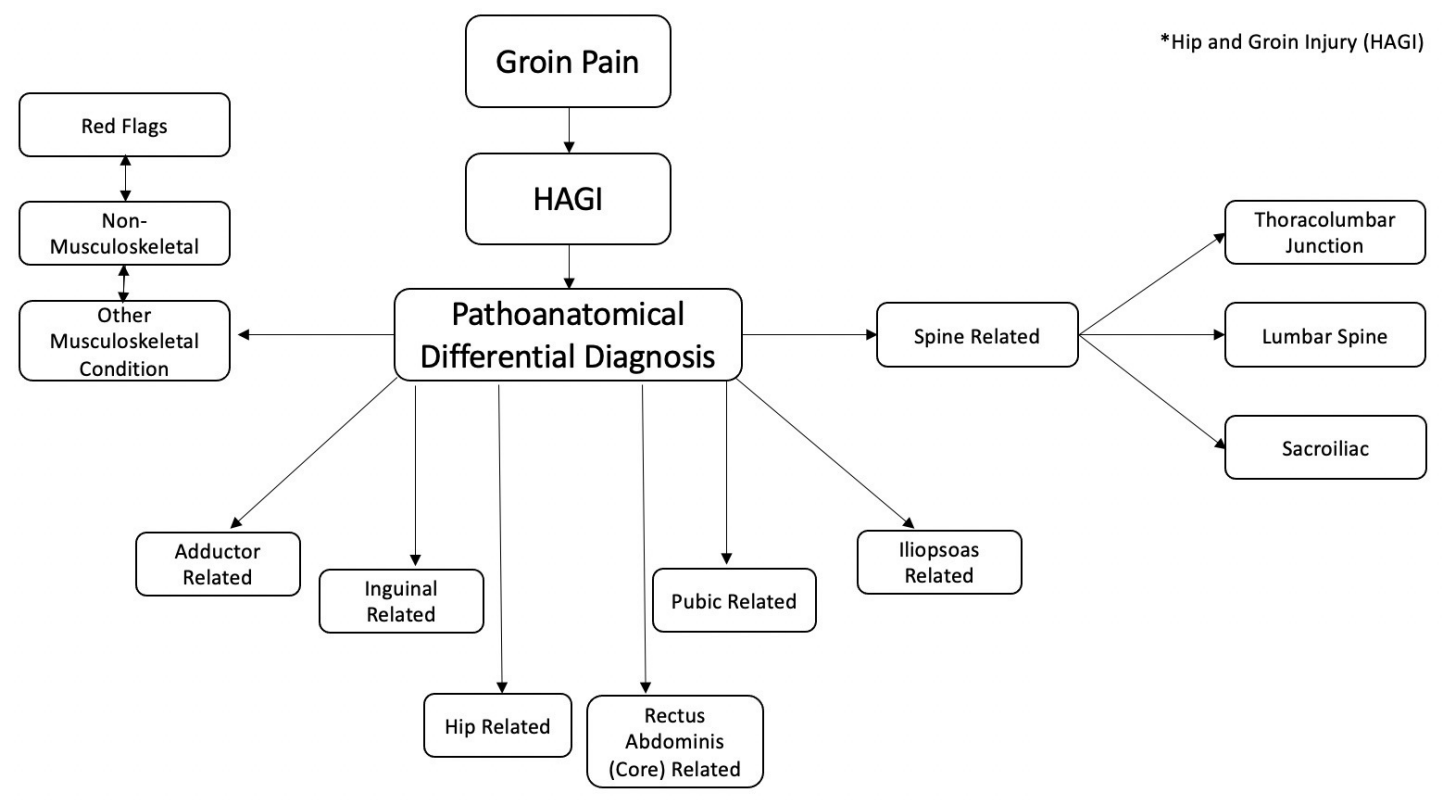

\section{Figure 1: Differential Diagnosis flow chart}

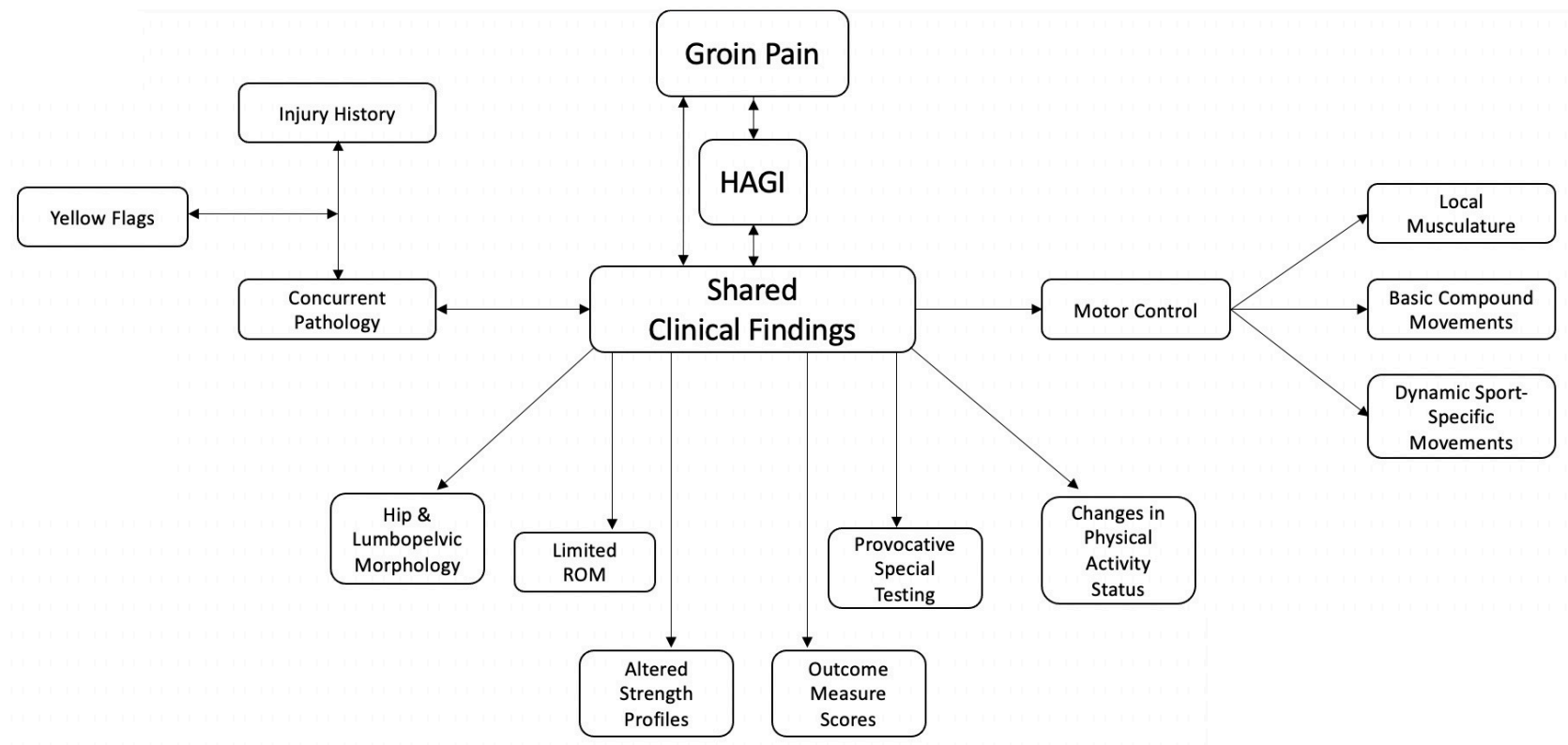

Figure 2: Shared Clinical Findings of Hip and Groin Injury flow chart

pairments such as mobility loss, strength deficits, and altered force distribution and motor control have been associated with these defined syndromes, ultimately affecting the athletic movement system. Thus, despite the diversity of specific pathoanatomy, shared clinical characteristics such as pain referral region and aforementioned residual impairment constructs (mobility, strength, motor control, deconditioning, etc) often present irrespective of sensitized or injured structure. ${ }^{12-14}$ (Figure 2)

Considering the persistent historical challenges associated with management of HAGI, warranted attention has been growing towards mitigating its impact before an ath- lete becomes medicalized. Risk reduction for HAGI is a hot topic with limited reported success, ${ }^{15}$ and the available literature-base to support practical, evidence-based practices across various elite sports is often limited and biased.16,17 Current prevention strategies are generally based upon soft-tissue injury while still broadly being grouped in the HAGI spectrum. ${ }^{18,19}$ Select populations (professional and semiprofessional soccer, rugby union, ice hockey) dominate the literature upon which current evidence-based practice relies. ${ }^{17}$ Professionals practicing in sports outside of those populations and specifically within sports such as basketball, American football, or elsewhere may be presented with 
athletes who are currently underrepresented in the literature. Considerations that raise questions regarding the carryover of current risk identification and treatment strategies to a wide range of athletes include, but are not limited to, anthropometric and biomechanical profiles, sport specific demands (i.e volume of short space cutting and jumping volume vs time at defined high speed running, etc) and differing historical practices of sports medicine and science in a team-based setting across sports and countries.

\section{REVIEWING THE CLINICAL QUESTION}

The New Oxford American Dictionary defines risk as the chance of unfortunate consequences by engaging in an action. ${ }^{20}$ In the case of athletics and exercise, the primary adverse event is musculoskeletal injury. The consequences of sporting injury are multifactorial, and can result in the worsening of mental and physical wellbeing as well as increasing the risk of future injury and disability. In elite sport, the consequence moves beyond individual harm, as competitive success and monetary investment are at stake. ${ }^{12,21}$ As sports medicine professionals, we have the potential to impact risk on microscopic and macroscopic scales. Our responsibility is to investigate methods to reduce the risk of the injury burden to our athletes, medical systems, and institutions. Despite what seems like overwhelming, yet diversely varying, ${ }^{16,17}$ consensuses on how to accomplish this goal, a critical investigation on injury prevention is necessary when trying to implement best practice in action for the field of play.

Caring for athletes involves navigating complex interacting systems which makes prediction and prevention quite challenging. ${ }^{22}$ Each sport exposes athletes to different risks and dynamic challenges and thus the initial steps in risk reduction are to identify common athletic demands and clinical problems. For example, in professional basketball, much effort has been put into the prevention of ankle and knee injury, as they have been identified as the most common and result in greatest time loss due to injury. Substantial attention has also been paid to catastrophic injuries, that often result in surgery, such as anterior cruciate ligament (ACL) rupture. As a result, research and clinical practice has focused on identification of related risk factor and prevention methods for such high-profile injuries. However, for example, in the National Basketball Association, all knee sprains, not just ACL tears, accounted for just $3.1 \%$ of all injuries over 17 seasons. ${ }^{23}$ Meanwhile, clinical cases of less investigated injuries, such as hip and groin injury (HAGI), have been identified as just as common, and are potentially increasing in occurence. ${ }^{4,23}$

While HAGI has been reported as $5-10 \%$ of injuries across multiple sports, in previously identified high risk sports HAGI has been reported to be a greater source of time loss, accounting for approximately $10-23 \%$ of all injury. ${ }^{12,18} \mathrm{Nu}-$ merous structures within the region can be drivers of pain and injury. Additional consideration is warranted for the likelihood of concurrent pathology, injury reoccurrence, the chronicity of varying regional pathologies, and suboptimal athletic and health care outcomes. ${ }^{1,2}$ As the diagnosis and management of HAGI remains challenging, efforts should be made to investigate and improve specific injury risk re- duction strategies to avert these historical challenges before they arise.

\section{IDENTIFIED RISK FACTORS}

Highlighted non-modifiable risk factors identified in the literature include past injury history, age, time in season, and anatomy and morphology. ${ }^{21}$ While injury history and age have consistent backing in the evidence base, utilizing diagnostic imaging for identifying a priori pathoanatomic risk factors may be challenging. 'Abnormal' and 'pathological' findings about the hip and pubis, such as cam morphology 2 or tendinous changes at the rectus abdominis and adductor longus origins, ${ }^{6}$ are commonly observed in asymptomatic athletes and may be sport specific adaptations. Of clinical interest are modifiable risk factors specific to the hip and groin including range of motion, hip and trunk strength, special testing, movement pattern assessment, and training variables. $^{21,24}$ The evidence behind these identified risk factors and the observed difficulties in their application will be highlighted.

\section{ANALYSIS OF 'MODIFIABLE' RISK FACTORS}

\section{RANGE OF MOTION}

Limited hip internal and external rotation in various positions, including seated, prone, bent knee fallout (flexion abduction external rotation), and the flexion adduction internal rotation (FADIR) test have all been related to HAGI. A measure of total hip rotation less than 85 degrees has also been identified as a risk factor. ${ }^{25}$ As with the consideration of total arc of motion compared to a single direction measure (such as the bent knee fall out), relative limb to limb range of motion and range of motion in sport specific positions may warrant deeper consideration as position specific findings may be related to injury. ${ }^{25,26}$ Clinical experience, unpublished data, and homogenous population data ${ }^{27}$ indicates that if clinicians are flagging ranges of motion (i.e 85 degrees total arc, bent knee fallout) as a risk factor cutoff point, nearly every athlete within select sports populations could be at risk due to limited hip mobility. In other words, if following the findings of systematic reviews, ${ }^{18,25}$ entire sporting populations would be defined as at risk of groin pain, limiting its effectiveness as a risk factor measure.

There is also a reliance on standardized ROM assessment of the hip which supports validity within studies, but may overlook the natural variance in pelvic morphology between individuals, especially when assessing hip internal rotation (IR). The natural arc of hip motion may vary between individuals due the variations in femoral version and acetabular alignment, such that an individual may demonstrate reduced hip IR in standard testing with excessive ER, but not when the individual's natural plane of hip motion (which could be defined as hiption, similar to the concept of scaption in the glenohumeral joint) is assessed. ${ }^{28}$ Further, this measure may be impacted by the timing of data collection, as rotation has been shown to change following competition $^{29}$ and may continue to be dynamic over the course of a season and career. ${ }^{30}$ 
Considering the prevalence of variations in athlete morphology and its complex relationship with mobility, how modifiable hip range of motion is warrants a more thorough investigation, as evidence for preventative interventions to address mobility deficits is limited and rarely included in reviews. ${ }^{18,27,31,32}$ Transient in-session range of motion increases made by modalities, manual therapy, and therapeutic exercise may be clinically important, potentially redistributing force or changing pain pressure thresholds. However lasting tissue change has not been documented nor have mobility-based intervention programs been identified as protective. ${ }^{32}$

\section{STRENGTH}

Strength measures about the hip and trunk have been related to hip and groin pain. Of consistent interest is absolute and relative adductor strength. Common assessment methods include squeeze testing, during which a sphygmomanometer is used to measure the maximal isometric ability of the adductors in various supine positions. Other primary strength measures include handheld and isokinetic dynamometry. ${ }^{18,26}$ Low strength ratios of hip adduction to abduction, and high hip flexion to extension ratios and trunk flexion to extension ratios have all been identified as risk factors. ${ }^{12,26}$ The timing of muscle activation may be meaningful, but it has not been determined as a cause or a result of HAGI and it is currently nearly impossible to identify functional motor recruitment in sport-specific context. Furthermore, documented standardized strength assessment may not accurately measure strength variables as they relate to sport-specific tasks and associated mechanisms of injury such as defensive shuffling, kicking, single leg jumping, or how an ongoing strength profile improves any tissue's capacity to handle such tasks. Simple strength metrics have been shown to vary according to population, ${ }^{33}$ morphology, ${ }^{27}$ timing, ${ }^{34}$ presence of pain, 33 fatigue, ${ }^{34}$ and many other factors indicating a need for clinical reasoning for interpretation and application.

Similar to hip range of motion, a clinical challenge of applying strength data is that current reference data is likely population and context specific. Most documented strength assessments are performed prior to competitive seasons and not intra-season. The differing sporting and training demands, as well as differences in athlete's biomechanical profile (i.e mechanical advantage according to leg length when performing long lever squeeze assessment) likely limits clinicians ability to interpret and apply normative data across sports, as empirical analysis of subgroup scores are quite different from current published values. ${ }^{33}$ If strength is assessed in-season or following competition, whether immediately or next day, there are minimal recommendations on the best ways to interpret or act on such information, particularly when considering congested competition schedules during which optimal recovery from intense activity is impaired. ${ }^{34-36}$

\section{SPECIAL TESTING}

Special testing often combines elements of range of motion and strength for symptom provocation and the tissue and/ or system impairments as they relate may indicate a level of risk for example squeeze testing ${ }^{37}$ and the FADIR test. ${ }^{38}$ Consistent monitoring of special tests may identify significant variance in prior findings and could be related to training volume or pain. ${ }^{34,39}$ These tests provide value for daily clinical reasoning in a dynamic test-retest model, but since these tests generally identify sensitized actions, structures, and/or movements, they are currently more valuable once the athlete is already nursing an injury as opposed to providing prognostic value.

\section{MOVEMENT ASSESSMENT}

Clinical movement assessments have been found to have minimal utility in identifying those at risk for hip and groin injury, despite potential construct validity. It has been shown that those with HAGI demonstrate different movement patterns in tasks of varying intensities compared to controls. ${ }^{40,41}$ Differences have been identified in star excursion balance test of posterolateral reach and altered intersegmental biomechanics in various cutting tasks in those with HAGI. ${ }^{42,43}$ Variable movement patterns during a cutting task have not been established as predictive of HAGI, however changes in these patterns, in addition to improved adductor strength, have been shown to occur with intersegmental-focused training when returning from a prior HAGI. ${ }^{43,44}$ It is unclear whether this assists in the cause of the resolution of injury or is changed due to the absence of pain and natural history. While training movement patterns is often a focus in physiotherapist practice, it warrants questioning whether changes in multi-segmental control and/or movement patterns transfers to sport specific and reactive variations of movements, or if changing asymptomatic movement patterns may provide a protective stimulus, and even potentially provide a false level of comfort to the clinician and athlete. With or without symptoms, it has been shown that efficient force distribution about the pelvis is recommended (i.e avoiding excessive trunk lean displacement, excessive displacement beyond the center of mass) and may have implications with HAGI. ${ }^{43-45}$

\section{MONITORING LOAD AND OBJECTIVE OUTCOME MEASURES}

Monitored training variables and resultant outcomes of sport training such as body composition, aerobic fitness, and sport-specific training load volume has been reported as related to injury risk. Load monitoring strategies vary greatly and include internal (physiologic) or external (mechanical) variables. ${ }^{46}$ For other highly studied injuries, such has hamstring strain, variables such as distance covered and high-speed running metrics have been documented as injury risk factors. ${ }^{39,47,48}$ It has been proposed that these factors should be applied across sports and injuries, without consideration of the differing demands of various sports. ${ }^{47}$ Court athletes may never achieve similar high speeds or distances as field athletes, while being stressed by different mechanical forces and associated physiologic consequences associated with tasks such as high volume jumping or limited-space, high intensity cutting maneuvers. ${ }^{49}$ Sport specific preparation has been identified as a common risk fac- 
tor, thus, an importance must be placed on defining and training these identified variables, yet are not commonly detailed in the literature, training or in sporting practice. ${ }^{49}$ In order for sport-specific training to be provided, these qualifiers must be defined, tested, and trained to evaluate their potential protective capacity. ${ }^{50}$ Practical challenges are numerous when attempting to consistently collect and utilize objective outcome measures, ${ }^{49}$ especially when considering clinical time demands, the substantial size of data sets, the impact of internal and external factors in elite sport, and the numerous athlete health and performance demands aside from HAGI that present in daily practice.

\section{PRACTICAL GAPS IN SCREENING}

Despite significant investigation, much debate continues to take place regarding the value of screening for athletic injury risk factors and its effectiveness has been extensively questioned. ${ }^{24,51}$ Current evidence pertaining to heterogenous HAGI risk factors is often disproportionately represented from select homogenous populations. Derivation of risk factors frequently relies on retrospective study design as opposed to more rigid prospectively designed trials. The lack of prospective studies is not shocking, as data collection and application in elite sport presents numerous practical challenges, including appropriate design, collection, sharing, and publication of relevant data. ${ }^{24,51}$ The culture and history of each individual sport presents with varying attitudes and opportunities to cultivating and prioritizing the development of research practices. ${ }^{49}$ These limitations leave questions as to whether or not sample sizes are robust enough to hold clinical value, if specific qualities are the result of, or potential cause of injury, if these factors are able to be shared across various sports and genders, or if risk reduction research and development can even take place in environments of interest. ${ }^{49}$

\section{INTERVENTION OVER IDENTIFICATION}

As opposed to a narrow focus on isolated risk factors, reducing the occurrence of hip and groin injury or otherwise may be best served by focusing on global neuromuscular training combined with individualized and context- specific 'prevention' programs that avoid training load error. ${ }^{52}$ With shared regional factors (mobility, strength, motor control, altered force distribution, tissue tolerance, etc) about HAGI, global principals are appropriate to apply to mitigation programs. Ultimately, achieving less injury may rely on an adequate volume and adherence of training in these risk reduction strategies, most specifically, appropriately dosed and performed exercise. ${ }^{32,53}$ Despite this working hypothesis, a general well planned, balanced, and executed multi-component exercise training program may be protective regardless of the targeted constructs listed above. ${ }^{15}$ Developing numerous qualities within the variables of strength and aerobic capacity may be key modifiers in decreasing an athlete's risk for HAGI regardless of underlying proposed risk factors defined earlier in this paper. ${ }^{53-55}$ Objective data obtained historically via traditional screening methods may not be predictive in a classical prevention ideology, but may con- tinue to hold secondary value in establishing baselines profiles, and be used to monitor progress and changes in the athletes dynamic system to inform clinical reasoning and athlete care. ${ }^{34,39,46,56,57}$ Monitoring profiles of strength and exercise load metrics are emerging as recommended evidence-based practice for secondary risk reduction allowing for clinicians to make real-time programming decisions to reduce risk. ${ }^{34,39,57}$ The nature of dosing requires further investigation, 58 as an adequate baseline and minimal effective dose of exercise may serve as protective. ${ }^{59}$ Timing the dose as it relates to match day and in relation to activity timing may provide improved adherence and effectiveness. ${ }^{59-62}$

Again, despite the heterogeneity of the pathology of HAGI, it is valuable to note the homogeneity of physiotherapist intervention. Education, assessment, exercise, movement training, appropriate mobility intervention, optimal dosing of intervention, and continued monitoring have all been commonly recommended in the comprehensive management of various hip joint, osseous and soft-tissue related injuries. 63 (Figure 3) Similarly, mobility, hip strength, and motor control are constructs that can be defined respectively as risk factors, injury impairments and rehabilitation goals. ${ }^{43,56}$ (Figure 4) The authors recommend that these same constructs be appropriately implemented into future focused risk reduction programs (Figures $\underline{5}$ and $\underline{6}$ ). As these trainable constructs have been consistently identified across the HAGI spectrum, ${ }^{43}$ targeting them appropriately could have a mediating effect on past and/or future injury. ${ }^{35,56}$ By focusing on these factors and treating each individual with respect to their sporting demands and body's specific natural adaptations, ${ }^{64}$ it may be possible to develop clinical guidelines for HAGI reduction similar to what has been done regarding ACL prevention. ${ }^{65}$ As evidence-informed recommendations have been globally applied to comprehensive knee injury reduction, ${ }^{65}$ with further development, the same could be done for HAGI. The nature of global training principles may result in significant similarities between these programs, which is to the benefit of their application.

Of course, the remedy is not as simple or as straight forward as it may seem. Similar to the discussion of highlighted risk factors above, the efficacy and effectiveness of these programs remains limited to the sports in which they have been trialed via the scientific process, integrated, individualized, and accepted as common practice. For example, detailed general programs have been trialed in sports such as European football but few other team based sports. ${ }^{15-17,52}$ This has been most recently identified in a systematic review detailing the challenges of finding level 1 evidence in elite sport and then applying strategies of lower levels of evidence with high levels of bias. ${ }^{16,17}$ Transference troubles have been seen clinically in recognized pathologybased prevention programs such as neuromuscular training to reduce knee injuries. Many such programs have been established related to a specific gender and age population (adolescent females) and mechanism of injury may be dissimilar when comparing across sports, gender, and sporting maneuvers ${ }^{65,66}$ (i.e dynamic valgus produced by jump landing vs change of direction task). 


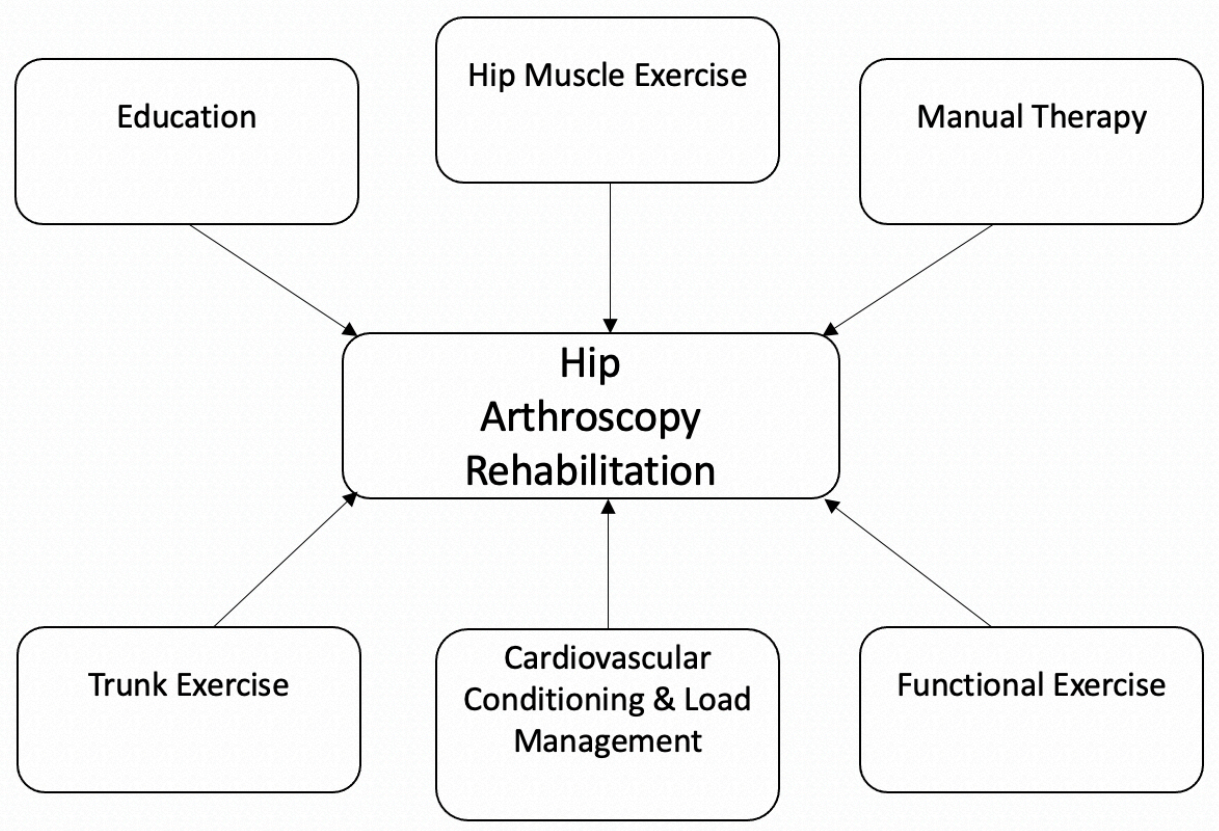

Figure 3: Construct recommendations for hip injury rehabilitation

Adapted and modeled from Heerey, J. et al. Impairment-based rehabilitation rollowing hip arthroscopy: Postoperative protocol for the HIP ARThroscopy international randomized controlled trial. J Orthop Sports Phys Ther. 2018;48(4):336-42. ${ }^{63}$

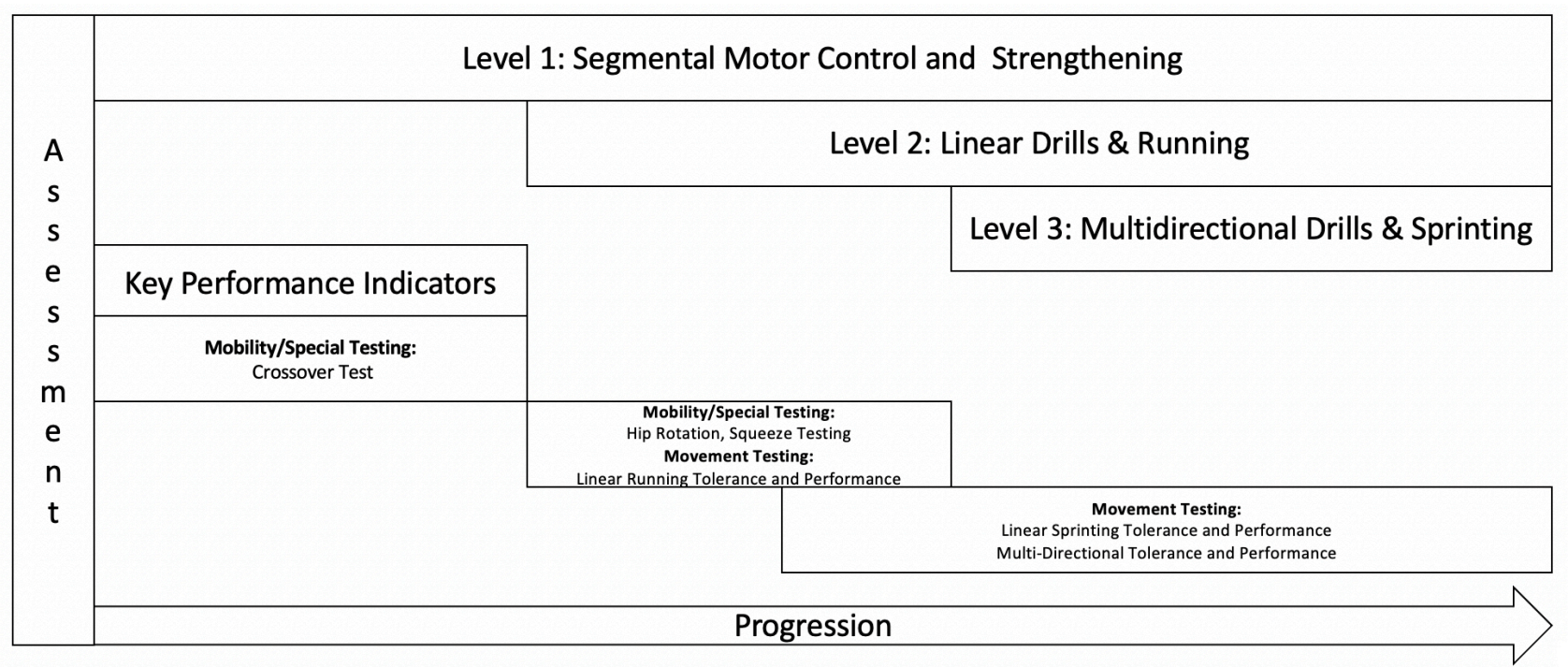

\section{Figure 4: Construct recommendations for groin injury rehabilitation}

Adapted and modeled from King E, Franklyn-Miller A, Richter C, et al. Clinical and biomechanical outcomes of rehabilitation targeting intersegmental control in athletic groin pain: prospective cohort of 205 patients. Br J Sports Med. 2018;52(16):1054-62.43

\section{CONCLUSIONS}

Identification of injuries with high incidence and prevalence within sport is common practice and leads to investigation of prevention, and more practically, risk reduction. In the case of HAGI, practitioners continue to rely on generalized risk factors and select populations to provide current best practice despite the growing number of identified
HAGI cases. Athletes across sports possess inherent characteristics that predispose them to specific sporting success, and may require a diverse set of risk modifying interventions to increase the odds of prolonged health and sports participation. In order to further improve these programs, the authors extend a call to action to refine important clinical questions and extensively test them in order to advance the practical evidence-base which may improve athlete health. This requires creating integrated institutions 


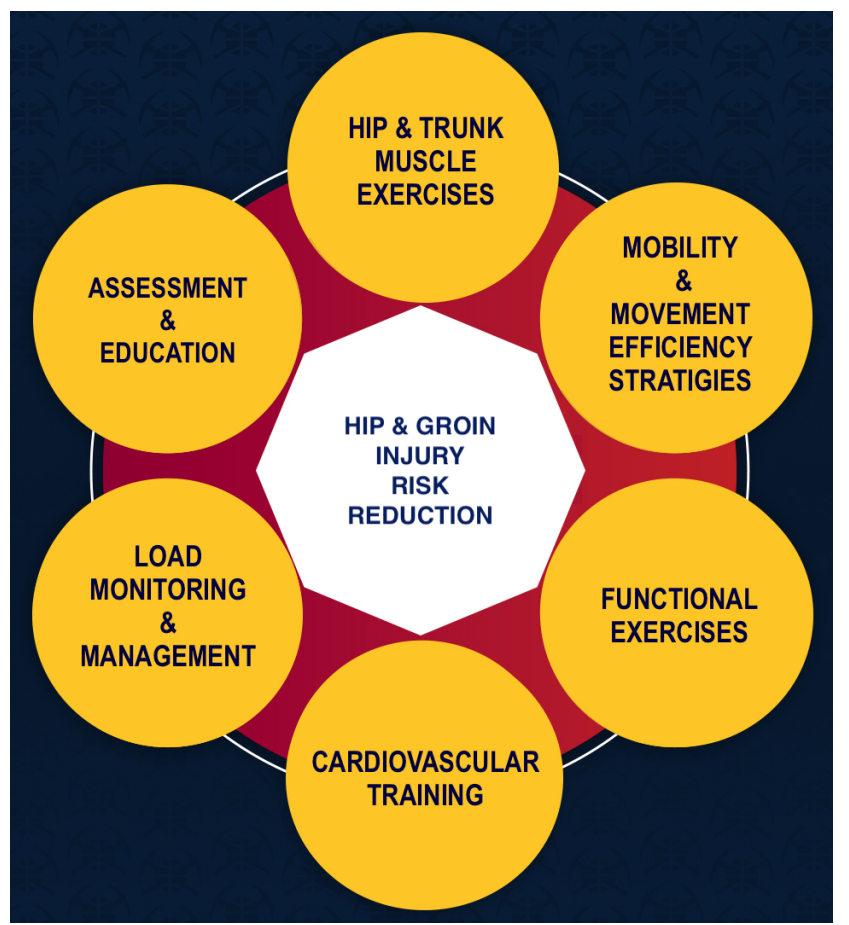

Figure 5: Applied construct recommendations for hip and groin injury risk reduction programs

Adapted and modeled from Heerey, J. et al. Impairment-based rehabilitation rollowing hip arthroscopy: Postoperative protocol for the HIP ARThroscopy international randomized controlled trial. J Orthop Sports Phys Ther. 2018;48(4):336-42.63

and avenues within all levels (youth, collegiate, semi-professional, professional) and geographical locations (including the United States) of sporting populations. This call to action can begin by proactively implementing current evidence-informed interventions, such as global exercise programs with injury-specific construct modifications, within diverse sporting populations. Assessing the residual outcomes and modifying programs accordingly could reverse trends of increasing HAGI in understudied populations. Until then, recommendations and practice will rely on clinical experience and at times liberal interpretations of practice across sporting populations.

\section{CONFLICT OF INTERESTS}

Authors declare no conflicts of interest

Submitted: December 19, 2019 CDT, Accepted: April 21, 2020

CDT 


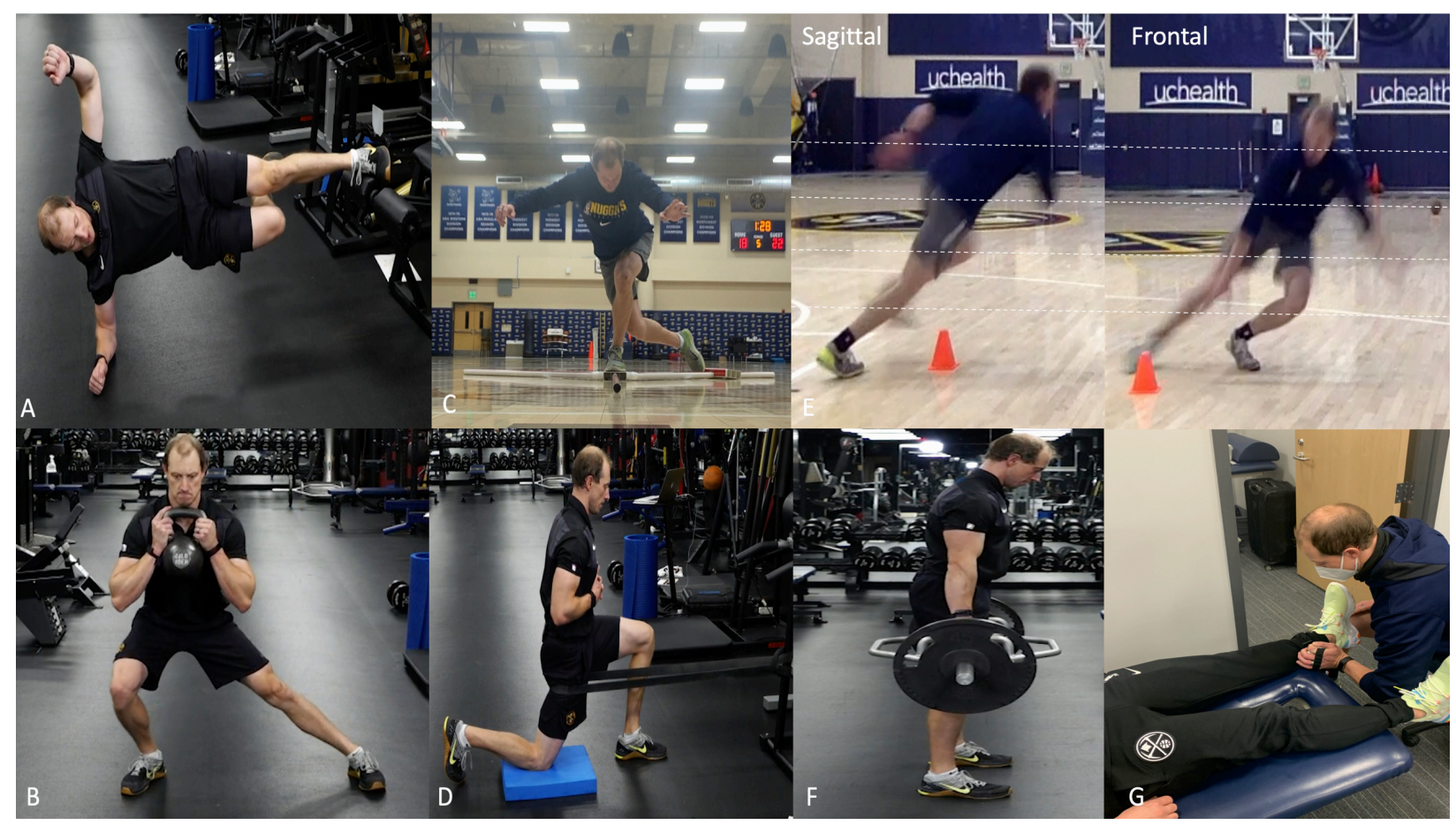

Figure 6: Implementation of Constructs into Risk Reduction Programs

A. Local hip and trunk strength via adductor side plank B. Functional exercises include single leg knee and hip dominant drills, here demonstrated by a lateral lunge C. Basic compound movement motor control trained by triplanar single leg tasks and can be monitored as demonstrated by the Y-Balance posterolateral reach D. Active assisted mobility exercise with considerations for the individuals hip and lumbopelvic morphology E. Sport-specific compound movement motor control. Sport training including practice and adjunct speed, agility, and quickness training can include the monitoring and coaching of desired mechanics while establishing sporting conditioning. Sagittal plane segmental movement goals include increased ankle dorsiflexion, and reduced knee flexion, anterior pelvic tilt, hip flexion and trunk flexion. Frontal plane segmental movement goals include reduced trunk rotation and side flexion, pelvic drop knee valgus, and foot external rotation. This may increase the power and work and the knee and ankle, while decreasing the demands on the hip and lumbopelvis. ${ }^{43}$ F. Functional exercise that trains hip, trunk, and compound movements as demonstrated by a hexbar deadlift G. Monitoring strategies are guided by baseline assessment and continued monitoring. Adduction strength is one variable that can be tracked, as well as other metrics such as additional strength measures, range of motion, and training load variables (i.e volume, intensity, etc) 


\section{REFERENCES}

1. Weir A, Brukner P, Delahunt E, et al. Doha agreement meeting on terminology and definitions in groin pain in athletes. $\mathrm{Br} J$ Sports $\mathrm{Med}$.

2015;49(12):768-774. doi:10.1136/bjsports-2015-0948 $\underline{69}$

2. Griffin DR, Dickenson EJ, O’Donnell J, et al. The Warwick Agreement on femoroacetabular impingement syndrome (FAI syndrome): an international consensus statement. Br J Sports Med. 2016;50(19):1169-1176. doi:10.1136/bjsports-2016-09 $\underline{6743}$

3. Thorborg K, Reiman MP, Weir A, et al. Clinical examination, diagnostic imaging, and testing of athletes with groin pain: An evidence-based approach to effective management. J Orthop Sports Phys Ther. 2018;48(4):239-249. doi:10.2519/jospt.2018.7850

4. Ekhtiari S, Khan M, Burrus T, et al. Hip and groin injuries in professional basketball players: Impact on playing career and quality of life after retirement. Sports Health. 2019;11(3):218-222. doi:10.1177/19417 $\underline{38119838274}$

5. Jackson TJ, Starkey C, McElhiney D, Domb BG. Epidemiology of hip injuries in the National Basketball Association: A 24-year overview. Orthop J Sports Med. 2013;1(3):2325967113499130. doi:10.117 $\underline{7 / 2325967113499130}$

6. Robinson P, Grainger AJ, Hensor EM, Batt ME, O'Connor PJ. Do MRI and ultrasound of the anterior pelvis correlate with, or predict, young football players' clinical findings? A 4-year prospective study of elite academy soccer players. Br J Sports Med. 2015;49(3):176-182. doi:10.1136/bjsports-2013-09293 $\underline{2}$

7. Thorborg K, Hölmich P. Advancing hip and groin injury management: from eminence to evidence. $\mathrm{Br} \mathrm{J}$ Sports Med. 2013;47(10):602. doi:10.1136/bjsports-20 12-092090

8. Reiman M, Boyd J, Ingel N, Reichert A, Westhoven $\mathrm{M}$, Peters S. There is limited and inconsistent reporting of postoperative rehabilitation for femoroacetabular impingement syndrome: A scoping review of 169 studies. J Orthop Sports Phys Ther. 2020;50(5):252-258. doi:10.2519/jospt.2020.9189

9. Strosberg DS, Ellis TJ, Renton DB. The role of femoroacetabular impingement in core muscle injury/ athletic pubalgia: Diagnosis and management. Front Surg. 2016;3:6. doi:10.3389/fsurg.2016.00006
10. Rivière C, Lazic S, Dagneaux L, Van Der Straeten C, Cobb J, Muirhead-Allwood S. Spine-hip relations in patients with hip osteoarthritis. EFORT Open Rev. 2018;3(2):39-44. doi:10.1302/2058-5241.3.170020

11. Munegato D, Bigoni M, Gridavilla G, Olmi S, Cesana G, Zatti G. Sports hernia and femoroacetabular impingement in athletes: A systematic review. World J Clin Cases. 2015;3(9):823-830. doi:10.12998/wjcc.v3.i9.823

12. Esteve E, Rathleff MS, Bagur-Calafat C, Urrutia G, Thorborg K. Prevention of groin injuries in sports: a systematic review with meta-analysis of randomised controlled trials. Br J Sports Med.

2015;49(12):785-791. doi:10.1136/bjsports-2014-0941 $\underline{62}$

13. Hammoud S, Bedi A, Voos JE, Mauro CS, Kelly BT. The recognition and evaluation of patterns of compensatory injury in patients with mechanical hip pain. Sports health. 2014;6(2):108-118. doi:10.1177/19 41738114522201

14. Short S, Short G, Strack D, Anloague P, Brewster B. A combined treatment approach emphasizing impairment-based manual therapy and exercise for hip-related compensatory injure in elite athletes: A case series. International journal of sports physical therapy. 2017;12(6):994-1010.

15. Haroy J, Thorborg K, Serner A, et al. Including the Copenhagen adduction exercise in the FIFA 11+ provides missing eccentric hip adduction strength effect in male soccer players: A randomized controlled trial. Am J Sports Med. 2017;45(13):3052-3059. doi:10.1177/03635465177201 $\underline{94}$

16. Ishøi L, Krommes K, Husted RS, Juhl CB, Thorborg $\mathrm{K}$. Diagnosis, prevention and treatment of common lower extremity muscle injuries in sport - grading the evidence: a statement paper commissioned by the Danish Society of Sports Physical Therapy (DSSF). Br J Sports Med. 2020:bjsports-2019-101228. doi:10.1136/ bjsports-2019-101228

17. Fanchini M, Steendahl IB, Impellizzeri FM, et al. Exercise-based strategies to prevent muscle injury in elite footballers: A systematic review and best evidence synthesis. Sports Med. 2020;50:1653-1666. $\underline{\mathrm{d}}$ oi:10.1007/s40279-020-01282-z

18. Mosler AB, Agricola R, Weir A, Holmich P, Crossley KM. Which factors differentiate athletes with hip/groin pain from those without? A systematic review with meta-analysis. Br J Sports Med. 2015;49(12):810. doi:10.1136/bjsports-2015-094602 
19. Mosler AB, Weir A, Serner A, et al.

Musculoskeletal screening tests and bony hip morphology cannot identify male professional soccer players at risk of groin injuries: A 2-year prospective cohort study. Am J Sports Med. 2018;46(6):1294-1305. doi:10.1177/0363546518763373

20. OED Online. Risk. In: New Oxford Dictionary. Oxford University Press; 2019.

21. Murphy DF, Connolly DAJ, Beynnon BD. Risk factors for lower extremity injury: a review of the literature. Br J Sports Med. 2003;37(1):13-29. doi:10.1 136/bism.37.1.13

22. Short S, Tuttle M. The gap betweem research and clinical practice for injury prevention im elite sport: A clinical commentary. Int J Sports Phys Ther. 2020;15(6):1229-1234. doi:10.26603/ijspt20201229

23. Drakos MC, Domb B, Starkey C, Callahan L, Allen AA. Injury in the national basketball association: a 17-year overview. Sports Health. 2010;2(4):284-290. d oi:10.1177/1941738109357303

24. Bahr R. Risk Factors for Sports Injuries a methodological approach. Br J Sports Med. 2003;37:384-392.

25. Tak I, Engelaar L, Gouttebarge V, et al. Is lower hip range of motion a risk factor for groin pain in athletes? A systematic review with clinical applications. Br J Sports Med. 2017;51(22):1611-1621. doi:10.1136/bjsports-2016-096619

26. Whittaker JL, Small C, Maffey L, Emery CA. Risk factors for groin injury in sport: an updated systematic review. Br J Sports Med. 2015;49(12):803-809. doi:10.1136/bjsports-2014-0942 $\underline{87}$

27. Mosler AB, Agricola R, Thorborg K, et al. Is bony hip morphology associated with range of motion and strength in asymptomatic male soccer players? J Orthop Sports Phys Ther. 2018;48(4):250-259. doi:10.2 519/jospt.2018.7848

28. MacDonald CW. Hip manual therapy for aging and older adults. Topics Geriatr Rehabil.

2016;32(2):106-113. doi:10.1097/TGR.0000000000000 $\underline{074}$

29. De-la-Cruz-Torres B, Abuín-Porras V, BlancoMorales M, et al. Acute effects of a single football training or match on passive hip rotation range of motion in semi-professional football players: A pilot study. Medicina. 2020;56(5):228. doi:10.3390/medicin $\underline{\mathrm{a} 56050228}$
30. Camp CL, Zajac JM, Pearson D, et al. The impact of workload on the evolution of hip internal and external rotation in professional baseball players over the course of the season. Orthop J Sports Med. 2018;6(2):2325967117752105. doi:10.1177/232596711 $\underline{7752105}$

31. van Klij P, Ginai AZ, Heijboer MP, Verhaar JAN, Waarsing JH, Agricola R. The relationship between cam morphology and hip and groin symptoms and signs in young male football players. Scand J Med Sci Sports. 2020;30:1221-1231. doi:10.1111/sms.13660

32. Brunner R, Friesenbichler B, Casartelli NC, Bizzini M, Maffiuletti NA, Niedermann K. Effectiveness of multicomponent lower extremity injury prevention programmes in team-sport athletes: an umbrella review. Br J Sports Med. 2019;53(5):282-288. doi:10.11 36/bjsports-2017-098944

33. Oliveras R, Bizzini M, Brunner R, Maffiuletti NA. Field-based evaluation of hip adductor and abductor strength in professional male ice hockey players: Reference values and influencing factors. Phys Ther Sport. 2020;43:204-209. doi:10.1016/j.ptsp.2020.03.00 6

34. Wollin M, Thorborg K, Welvaert M, Pizzari T. Inseason monitoring of hip and groin strength, health and function in elite youth soccer: Implementing an early detection and management strategy over two consecutive seasons. J Sci Med Sport. 2018;21(10):988-993. doi:10.1016/i.jsams.2018.03.00 4

35. Malone S, Hughes B, Doran DA, Collins K, Gabbett TJ. Can the workload-injury relationship be moderated by improved strength, speed and repeated-sprint qualities? J Sci Med Sport. 2019;22(1):29-34. doi:10.1016/i.jsams.2018.01.010

36. Wörner T, Thorborg K, Eek F. Five-second squeeze testing in 333 professional and semiprofessional male ice hockey players: How are hip and groin symptoms, strength, and sporting function related? Ortho J Sports Med.

2019;7(2):2325967119825858-2325967119825858. do i:10.1177/2325967119825858

37. Thorborg K, Branci S, Nielsen MP, Langelund MT, Holmich P. Copenhagen five-second squeeze: a valid indicator of sports-related hip and groin function. $\mathrm{Br}$ J Sports Med. 2017;51(7):594-599. doi:10.1136/bjsport s-2016-096675

38. King MG, Semciw AI, Hart HF, et al. Sub-elite football players with hip-related groin pain and a positive flexion, adduction, and internal rotation test exhibit distinct biomechanical differences compared with the asymptomatic side. J Orthop Sports Phys Ther. 2018;48(7):584-593. doi:10.2519/jospt.2018.791 $\underline{0}$ 
39. Wollin M, Thorborg K, Pizzari T. Monitoring the effect of football match congestion on hamstring strength and lower limb flexibility: Potential for secondary injury prevention? Phys Ther Sport. 2018;29:14-18. doi:10.1016/j.ptsp.2017.09.001

40. Whittaker JL, Booysen N, de la Motte S, et al. Predicting sport and occupational lower extremity injury risk through movement quality screening: a systematic review. Br J Sports Med. 2017;51(7):580-585. doi:10.1136/bjsports-2016-09676 $\underline{0}$

41. Hegedus EJ. The association of physical performance tests with injury in collegiate athletes. Br J Sports Med. 2017;51(13):1039-1040. doi:10.1136/ bjsports-2016-097223

42. Johansson AC, Karlsson H. The star excursion balance test: Criterion and divergent validity on patients with femoral acetabular impingement. Man Ther. 2016;26:104-109. doi:10.1016/j.math.2016.07.01 $\underline{5}$

43. King E, Franklyn-Miller A, Richter C, et al. Clinical and biomechanical outcomes of rehabilitation targeting intersegmental control in athletic groin pain: prospective cohort of 205 patients. Br J Sports Med. 2018;52(16):1054-1062. doi:10.1136/bjsports-20 $\underline{16-097089}$

44. Franklyn-Miller A, Richter C, King E, et al. Athletic groin pain (part 2): a prospective cohort study on the biomechanical evaluation of change of direction identifies three clusters of movement patterns. Br J Sports Med. 2017;51(5):460-468. doi:1 0.1136/bjsports-2016-096050

45. Edwards S, Brooke HC, Cook JL. Distinct cut task strategy in Australian football players with a history of groin pain. Phys Ther Sport. 2017;23:58-66. doi:1 0.1016/i.ptsp.2016.07.005

46. Impellizzeri FM, Marcora SM, Coutts AJ. Internal and External Training Load: 15 Years On. Int J Sports Physiol Perform. 2019;14(2):270-273. doi:10.1123/ijsp p.2018-0935

47. Gabbett TJ. Debunking the myths about training load, injury and performance: empirical evidence, hot topics and recommendations for practitioners. $\mathrm{Br} \mathrm{J}$ Sports Med. 2018:bjsports-2018-099784. doi:10.1136/ bjsports-2018-099784

48. Buckthorpe M, Wright S, Bruce-Low S, et al. Recommendations for hamstring injury prevention in elite football: translating research into practice. $\mathrm{Br} \mathrm{J}$ Sports Med. 2019;53(7):449-456. doi:10.1136/bjsport $\underline{\mathrm{s}-2018-099616}$
49. McLean BD, Strack D, Russell J, Coutts AJ. Quantifying physical demands in the National Basketball Association-challenges around developing best-practice models for athlete care and performance. Int J Sports Physiol Perform. 2019;14(4):414-420. doi:10.1123/ijspp.2018-0384

50. Russell JL, McLean BD, Impellizzeri FM, Strack DS, Coutts AJ. Measuring physical demands in basketball: an explorative systematic review of practices. Sports Med. 2020. doi:10.1007/s40279-02 $\underline{0-01375-9}$

51. Bahr R. Why screening tests to predict injury do not work-and probably never will...: a critical review. Br J Sports Med. 2016;50(13):776-780. doi:10.1136/bjs ports-2016-096256

52. Thorborg K, Krommes KK, Esteve E, Clausen MB, Bartels EM, Rathleff MS. Effect of specific exercisebased football injury prevention programmes on the overall injury rate in football: a systematic review and meta-analysis of the FIFA 11 and $11+$ programmes. $\mathrm{Br}$ J Sports Med. 2017;51(7):562-571. doi:10.1136/bjsport s-2016-097066

53. Lauersen JB, Andersen TE, Andersen LB. Strength training as superior, dose-dependent and safe prevention of acute and overuse sports injuries: a systematic review, qualitative analysis and metaanalysis. Br J Sports Med. 2018;52(24):1557-1563. do i:10.1136/bjsports-2018-099078

54. de la Motte SJ, Lisman P, Gribbin TC, Murphy K, Deuster PA. Systematic review of the association between physical fitness and musculoskeletal injury risk: Part 3-flexibility, power, speed, balance, and agility. J Strength Cond Res. 2019;33(6):1723-1735. do i: $10.1519 /$ JSC.0000000000002382

55. Lisman PJ, de la Motte SJ, Gribbin TC, Jaffin DP, Murphy K, Deuster PA. A systematic review of the association between physical fitness and musculoskeletal injury risk: Part 1-cardiorespiratory endurance. J Strength Cond Res.

2017;31(6):1744-1757. doi:10.1519/jsc.000000000000 $\underline{1855}$

56. Hegedus EJ, McDonough S, Bleakley C, et al. Physical performance tests predict injury in National Collegiate Athletic Association athletes: a threeseason prospective cohort study. Br J Sports Med. 2016;50(21):1333-1337. doi:10.1136/bjsports-2015-09 $\underline{4885}$

57. Wollin M, Thorborg K, Drew M, Pizzari T. A novel hamstring strain injury prevention system: postmatch strength testing for secondary prevention in football. Br J Sports Med. 2019:bjsports-2019-100707. doi:10.1136/bjsports-2019-100707 
58. Page P, Hoogenboom B, Voight M. Improving the reporting of therapeutic exercise interventions in rehabilitation research. Int J Sports Phys Ther. 2017;12(2):297-304.

59. Cuthbert M, Ripley N, McMahon JJ, Evans M, Haff GG, Comfort P. The effect of nordic hamstring exercise intervention volume on eccentric strength and muscle architecture adaptations: A systematic review and meta-analyses. Sports Med. 2019;50:83-99. doi:10.1007/s40279-019-01178-7

60. Whalan M, Lovell R, Steele JR, Sampson JA. Rescheduling Part 2 of the $11+$ reduces injury burden and increases compliance in semi-professional football. Scand J Med Sci Sports. 2019;29:1941-1951. d oi:10.1111/sms.13532

61. Lovell R, Whalan M, Marshall PWM, Sampson JA, Siegler JC, Buchheit M. Scheduling of eccentric lower limb injury prevention exercises during the soccer micro-cycle: Which day of the week? Scand J Med Sci Sports. 2018;28(10):2216-2225. doi:10.1111/sms.1322 $\underline{6}$

62. Androulakis-Korakakis P, Fisher JP, Steele J. The Minimum Effective Training Dose Required to Increase 1RM Strength in Resistance-Trained Men: A Systematic Review and Meta-Analysis. Sports Med. 2020;50(4):751-765. doi:10.1007/s40279-019-01236-0
63. Heerey J, Risberg MA, Magnus J, et al. Impairment-based rehabilitation following hip arthroscopy: Postoperative protocol for the HIP ARThroscopy international randomized controlled trial. J Orthop Sports Phys Ther. 2018;48(4):336-342. d oi:10.2519/jospt.2018.8002

64. Palmer A, Fernquest S, Gimpel M, et al. Physical activity during adolescence and the development of cam morphology: a cross-sectional cohort study of 210 individuals. Br J Sports Med. 2018;52(9):601. doi:1 $\underline{0.1136 / \text { bjsports-2017-097626 }}$

65. Arundale AJH, Bizzini M, Giordano A, et al. Exercise-based knee and anterior cruciate ligament injury prevention. J Orthop Sports Phys Ther. 2018;48(9):A1-a42. doi:10.2519/jospt.2018.0303

66. Schache AG, Woodley SJ, Schilders E, Orchard JW, Crossley KM. Anatomical and morphological characteristics may explain why groin pain is more common in male than female athletes. Br J Sports Med. 2017;51(7):554-555. doi:10.1136/bjsports-201 6-096945 